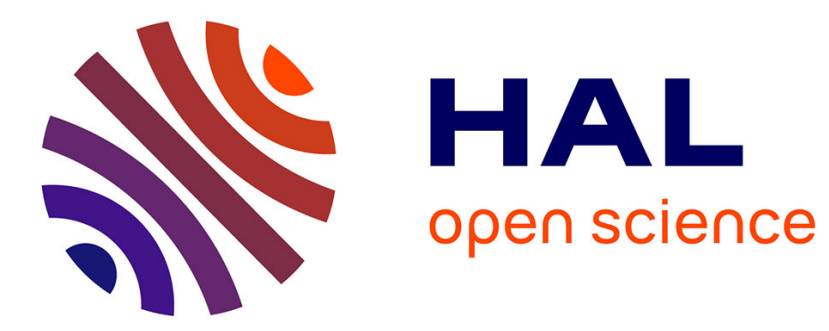

\title{
Donating organs: A theory-driven inventory of motives
} Myriam Guedj, María Teresa Muñoz-Sastre, Etienne Mullet

\section{To cite this version:}

Myriam Guedj, María Teresa Muñoz-Sastre, Etienne Mullet. Donating organs: A theorydriven inventory of motives. Psychology, Health and Medicine, 2011, 16 (4), pp.418-429. 10.1080/13548506.2011.555770 . hal-01953062

\section{HAL Id: hal-01953062 \\ https://hal-univ-tlse2.archives-ouvertes.fr/hal-01953062}

Submitted on 12 Dec 2018

HAL is a multi-disciplinary open access archive for the deposit and dissemination of scientific research documents, whether they are published or not. The documents may come from teaching and research institutions in France or abroad, or from public or private research centers.
L'archive ouverte pluridisciplinaire HAL, est destinée au dépôt et à la diffusion de documents scientifiques de niveau recherche, publiés ou non, émanant des établissements d'enseignement et de recherche français ou étrangers, des laboratoires publics ou privés. 
DONATING ORGANS: A THEORY-DRIVEN INVENTORY OF MOTIVES M. Guedj ${ }^{(1)}$, M.T.Munoz-Sastre ${ }^{(1)}$, E.Mullet ${ }^{(2)}$

\author{
${ }^{(1)}$ Université Toulouse le Mirail, Toulouse, France \\ ${ }^{(2)}$ Ecole Pratique des Hautes Etudes, Toulouse, France
}


Abstract

Two studies examined in a theoretically driven way the full range of motives that lay behind patients' acceptance or reluctance at donating organs after death. They also examined the way these motives were related to demographic characteristics, to the personality, and to the signing of a donor card. Six separable motives at donating organ were evidenced, and these motives were interpretable in the Reversal Theory framework: Financial Incentive (telic), Humanistic or Religious Duty (conformist), Positive Consideration from Others (autocentric sympathy), Living on Through a Receiver (pro-autic mastery), and Gift of Life and Close Others (allocentric sympathy). Five motives at not donating organs were evidenced: Preserving the Absolute Integrity of the Body (conformist), Strict Individualism (negativist), Lack of Control over the Use of the Organs (autocentric mastery), Anonymity of the Procedure (autocentric sympathy), and Respecting Family Wishes (allocentric sympathy). These motives were linked to personality factors in a meaningful way. Willingness to sign was strongly associated with gender, with Integrity and Duty, and with Gift of Life. When Integrity scored high, however, the effect of the other factors was practically annihilated. In other words, Integrity acted as a protected value (189 words).

Key words: organ donation, Reversal theory, motives, personality

Word count: 4,800 words 


\section{Donating Organs: A Theory-Driven Inventory of Motives}

The determinants of organ donation have been intensely examined. Many factors likely to explain the willingness to donate have been considered: organisational (Matesanz \& Dominguez-Gil, 2007), demographic, including cultural (Mocan \& Tekin, 2007), cognitive (Shanteau \& Skowronski, 1990,), attitudinal (Skowronski, 1997), representational (Moloney, Hall, \& Walker, 2005), personal (Besser, Amir, \& Barkan, 2004), and affective (Van den Berg, Manstead, Van der Pilgt, \& Wigboldus, 2005). Motivational factors have generally not been considered as such although findings that were difficult to explain (e.g., the specific behavior of minorities) have been tentatively related to motivational factors. The present set of studies examined, in a theoretically driven way, the full range of motives that lay behind patients' acceptance or reluctance at donating organs after death. It also examined the way these motives were related to demographic characteristics, to the personality, and to the signing of a donor card.

Among the motives that have been suggested for explaining willingness to donate, one can quote (a) financial incentives (Crowley-Matoka \& Lock, 2006), (b) moral and religious reasons (a "gift of life") (Hübner \& Kaiser, 2006), (c) improving self-esteem and making good impression to others (Brug, Van Vugt, Van den Borne, Brouwers \& Van Hooff, 2000), (d) altruism and solidarity (Sanner, 2006), (e) helping a known individual or a family member who is ill (Shanteau \& Skowronski, 1990), and (f) as a way of living on through another person (Crowley-Matoka \& Lock, 2006). Among the motives suggested for explaining unwillingness to donate, one can quote: (a) lack of knowledge (Radecki \& Jaccard, 1997), (b) absolute respect for the dead body, (Sque, Payne \& Macleod Clark, 2006), (c) respect for laws of nature (Sanner, 2006), (d) distrust about the physicians (Sanner, 2006), (e) fear that organs 
being removed before death (Callender \& Miles, 2001), (f) possible body disfigurement, (g) absorption by the receiver of one's identity (Sanner, 2006), (h) respecting the family's wishes (Radecki Breitkopf, 2006), et (i) not distressing an already bereaved family (Sque, Payne \& Macleod Clark, 2006).

In view of this diversity of motives, the theoretical framework chosen for examining them was a theory able to encompass this diversity: Reversal Theory (RT, Apter, 2001, 2007). This framework had already been used by Apter and Spirn (1997) for examining the motives that lay behind blood donation. Apter observed that people's ways of dealing with the world can be classified with reference to four fundamental domains or axes. Each of these axes has two opposite poles or metamotivational state, i.e., ways of experiencing one's motivations. The first domain deals with the experience of goals and means, and its contrasting metamotivational states are "telic" (focusing on goals and achievement, with a serious attitude) and "paratelic" (focusing on the activity in itself and on present moment, with a playful attitude). The second domain deals with the experience of rules and constraints, and its contrasting metamotivational states are "conformist" (following social codes, rules and laws; showing respect or obedience; adopting a conventional attitude) and "negativistic" (opposing social expectations and rules; expressing hostility or dissidence; adopting an unconventional attitude). The third domain deals with the experience of relationships with other people, things, or situations, and its metamotivational states are "autic" (focusing on one's own concerns and interests) and "alloic" (identifying with and focusing on the needs and interests of others). The fourth domain deals with the experience of transactions or exchanges with other people, things or situations and its contrasting metamotivational states are "mastery" (trying to dominate people, things or situations) and "sympathy" (feeling affection toward other people or things). 
Apter found that people are likely to be in metamotivational states from more than one domain at the same time and that they change states frequently during everyday life. In particular, the autic, alloic, mastery and sympathy states of mind tend to combine into four complexes: autic mastery, autic sympathy, alloic mastery and alloic sympathy. In addition, these complex states can take several forms. In the autocentric mastery and autocentric sympathy states, the person is motivated at mastering others or at being at the center of other's sympathy. In the allocentric mastery and allocentric sympathy states, the other persons are the dominating ones or the ones who are sympathized with. In the pro-autic mastery and pro-autic sympathy states, the person identifies himself or herself with a powerful other or with a sympathetic other in order to gain a personal impression of powerfulness or sympathy.

The objectives of the present studies were (a) inventorying the motives for donating or not donating organs, using the RT framework, (b) ordering these motives as a function of their perceived importance, (c) finding out how demographic characteristics were associated with these motives, and (d) finding out how these motives are associated with the willingness to sign a donor card.

\section{Study 1}

Study 1 was exploratory in character. Two questionnaires containing a whole range of motives for donating organs or not donating organs were presented to the participants. Through factor analyses, two motivational structures were delineated. We expected that these motivational structures would be interpretable in the RT framework. In particular, we expected people to describe their motives at donating organs as primarily reflecting allocentric sympathy type concerns (One of the motives why I would be willing to donate organs is that it can save many lifes), conformist type concerns (my religion or my philosophical views encourages me to do so), pro-autic mastery type concerns (I would be happy to live on through somebody else), and autocentric sympathy type concerns (people 
would keep the impression that I was a generous person). We also expected that the receiver's identity would be part of a specific motive (my organs would benefit a member of the family) (Skowronsky, 1997).

Regarding the motives at not donating organs, we expected people to describe them as primarily reflecting autocentric mastery type concerns (I do not know what is going to be done with them), conformist type concerns (I am responsible for the complete integrity of my body), autocentric sympathy type concerns (the receiver will not known in advance that I am the donor), and allocentric sympathy type concerns (this would be going against my family's wishes).

\section{Participants}

The sample was a convenience sample. All participants were unpaid volunteers. They were recruited and tested by two research assistants. Some of the young adults were recruited at the university. The other participants were recruited on the city sidewalks. Each research assistant contacted about 200 people, explained the study and asked them to participate. All came from Toulouse (a city of 1,000,000 inhabitants in South-Western France) and were born in France. The participation rate was $67 \%$.

The participants were 271 adults (184 females and 87 males) aged 18 to 73 ( $M=37.5$, $S D=12.5$ ). Twenty-six percent of the participants lived alone, $38 \%$ were married, $25 \%$ were in cohabitation, $8 \%$ were divorced, and $2 \%$ were widowed. Fifteen percent of the participants had not completed secondary school, $46 \%$ had completed secondary school but did not have a university degree, and 39\% had a university degree. Sixty-seven percent of the participants declared they believe in God, and 6\% were regular attendees. All the elderly participants lived independently.

\section{Material}


The first questionnaire comprised 48 items referring to possible motives to donate organs after death (see Table 1). These items included motives derived from all motivational states defined in the Reversal Theory. The common wording of all items - "One of the reasons why I would be willing to donate organs..." - was chosen to reflect the fact that several motives can be operating at the same time. The two extremes of the response scales were labeled "Complete disagreement" and "Complete agreement".

Half of the items were inspired from Parisi and Katz (1986). The other items were extracted from a large group of sentences proposed spontaneously by people during interviews. Fifteen persons considering organ donation were contacted before the study and instructed to list all the possible motives for donating organs (personal motives as well as motives they were told by other patients and/or family members and friends). The ones that best reflected the diversity of motives subsumed in the RT framework were retained. The second questionnaire comprised 50 sentences. It was created by applying the same principles. Procedure

Participants responded individually, at home or at the university (depending on the participant's preference). Most often, the participant immediately accompanied the experimenter to the chosen site. The experimenter was, in most cases, not present when the participants filled out the questionnaires (mainly in order not to influence them). Completion of the questionnaires took approximately 30 minutes. Half of the sample was presented the donating organs version first and the other version second. The second half of the sample was presented the questionnaires in the reverse order.

\section{Results}

An exploratory factor analysis was conducted on the 48 motives to donate organs. As many items did not load $(<.30)$ on any factor, they were removed, and a second exploratory factor analysis was conducted on the 28 remaining items. Based on the scree test, six 
interpretable factors emerged. This six-factor solution was retained and subjected to VARIMAX rotation.

The first factor explained $20 \%$ of the variance. It was called Gift of Life since it loaded items linked with the idea that many ill persons are waiting for organs, and that it would no be tolerable letting them suffer. The second factor (11\% of the variance) was called Positive Consideration from Others since it loaded items expressing the idea that donating organ usually attract other's consideration. The third factor (10\%) was called Living on Through a Receiver since it loaded items linked with the idea that one can survive by donating organs to other persons. The fourth factor (8\%) was called Financial Incentive since it expressed the view that a financial compensation to the family would be a great incentive. The fifth factor (8\%) was called Humanistic or Religious Duty since it loaded items expressing the idea that helping other persons is a duty that more and more persons want to fulfil. Finally the sixth factor (5\%) strongly loaded on just two items. It was called Close Others since it loaded on items expressing the view that donating organs to a family member is felt as easier than donating organs to an unknown person.

The same procedure was applied to the motives not to donate organs, and a five-factor structure was retained. The first factor (14\%) was called Lack of Control over the Use of the Organs since it loaded items expressing the idea that one cannot know what exactly has been done with the organs. The second factor (11\%) was called Respecting Family Wishes since it loaded items linked with the idea that the family would be upset if one of its members donates organs. The third factor (12\%) was called Anonymity of the Procedure since it loaded items linked with the idea that one cannot personally know the person who is going to receive one's organs. The fourth factor (13\%) was called Strict Individualism since it expressed the view that each person is fully responsible of her own destiny. Finally, the fifth factor (12\%) was 
called Preserving the Absolute Integrity of the Body since it loaded items linked with the idea that integrity of the body must be preserved.

A score was computed for each factor by simply averaging the values observed on the four items with the highest loadings. The highest score $(M=14.84, S D=2.84)$ was for Gift of Life, followed by Close Others ( $M=12.08, S D=4.12)$, Lack of Control $(M=6.81, S D=4.48)$, Duty (M=6.54, $S D=3.51)$, Living on Through a Receiver $(M=5.16, S D=4.24)$, Positive Consideration $(M=4.23, S D=3.34)$, Integrity $(M=4.38, S D=3.90)$, Anonymity $(M=3.44$, $S D=3.57)$. Respecting Family Wishes $(M=2.80, S D=3.04)$, Financial Incentive $(M=2.69$, $S D=2.55)$, and Individualism $(M=2.00, S D=2.03)$.

Study 2

Study 2 was confirmatory in character. It was also aimed at examining (a) the associations between demographic and personality characteristics and the motives, and (b) the association between the motives and the other variables, and the willingness to sign a donor card. We expected that willingness to sign should be strongly associated with gender (Mocan $\&$ Tekin, 2007), with conformist type motives and with allocentric sympathy type motives (Besser, Amir \& Barkan, 2004), and should be more strongly associated with the negative motives than with the positive motives (see, Brug et al., 2000, Skowronsky, 1997).

\section{Participants}

The sample was constituted in the same way as in Study 1. Participants were 102 adults (71 females and 31 males) aged 18 to $77(M=36.7, S D=16.5)$. Forty-four percent of them lived alone, $25 \%$ were married, $18 \%$ were in cohabitation, $12 \%$ were divorced, and $2 \%$ were widowed. Twenty-eight percent of the participants had not completed secondary school, $42 \%$ had completed secondary school but did not have a university degree, and $29 \%$ had a university degree. Sixty-three percent of them declared they believe in God, and $18 \%$ were regular attendees. 


\section{Material and Procedure}

The first two questionnaires (of motives) were composed on the basis of the results in Study 1. The items are shown in Tables 1 and 2. The third questionnaire was composed of 50 items taken from the International Pool of Items of Personality (IPIP, Goldberg, 1999). The fourth questionnaire was the Behavioral Commitment Toward Organ Donation questionnaire (BCTOD, Parisi \& Katz, 1986).

\section{Procedure}

The first three questionnaires were presented in close succession but, as in Study 1, in different orders. The BCTOD questionnaire was presented later, after the participants had completed another task that was unrelated to the study.

\section{Result}

A Confirmatory factor analysis was conducted on the motives to donate. The model tested is shown in Table 1. In view of obtaining a number of participants-number of variables ratio that was as high as possible, two parcels were created for each factor by averaging the values of two related items. The GFI value was .94; the CFI value was .98; the RMSEA value was .02[.00-.06], and the $\mathrm{Chi}^{2} / d f$ ratio was 1.02. A second Confirmatory factor analysis was conducted on the motives not to donate (see Table 2). The corresponding values were .94, $.98 ., .04[.00-.09]$, and 1.24.

Table 3 shows the correlations between demographic characteristics and personality, and motives. Gender mainly impacted on Individualism. This motive was less strongly endorsed by females than by males. Age was negatively associated with Positive Consideration. Education was negatively associated with Individualism. Being already a blood donor was negatively associated with Financial Incentives. Personally knowing someone in need of a transplantation was negatively associated with Integrity. Neuroticism was positively associated with Living on Through a Receiver. Extraversion was positively 
associated with Positive Consideration. Consciensciousness was positively associated with Financial Incentives. Agreeableness was negatively associated with Strict Individualism. (Openess did not significantly correlated with any motive). Table 3 also shows the correlations between motives and willingness to sign a donor card. The strongest link was with Integrity.

A stepwise regression analysis was conducted with willingness to sign as the criterion and (a) the demographic characteristics variables (except blood donation), which were entered first, (b) the personality measurements, which were entered second, and (c) the motives, which were entered third. Le demographic characteristics explained $18 \%$ of the variance, $\mathrm{F}(7,94)=2.95, \mathrm{p}<.01$. The personality measurements explained an additional $3 \%, n s$. The motives explained an additional $31 \%, \mathrm{~F}(11,78)=4.60, \mathrm{p}<.001$.

A second stepwise regression analysis was conducted with the predictors entered separately. Only three motives -- Integrity(Beta=-.47), Duty (Beta=.25), and Gift (Beta=.16), and only one demographic characteristic - Gender $($ Beta=.18) -- were significantly associated with willingness to sign, and they explained $42 \%$ of the variance, $F(4,97)=17.64, p<.001$. These three motive scores were dichotomized and willingness to sign was plotted against these factors. As shown in Figure 1, an Integrity x Duty interaction was present, $F(1,98)=6.59$, $\mathrm{p}<.02$, as well as an Integrity $x$ Gift interaction, $\mathrm{F}(1,98)=6.82, \mathrm{p}<.02$.

\section{General Discussion}

These two studies were aimed at inventorying the motives of people for donating or not donating organs after death, using the RT framework. Overall, eleven separable motives were evidenced, and these motives were, as expected, interpretable in the RT framework: Financial Incentive was a telic factor, Humanistic or Religious Duty and Preserving the Absolute Integrity of the Body were conformist factors, Strict Individualism was a negativist factor, Lack of Control over the Use of the Organs was an autocentric mastery factor, Positive 
Consideration from Others and Anonymity of the Procedure were autocentric sympathy factors, Living on Through a Receiver was a pro-autic mastery factor and Gift of Life and Respecting Family Wishes were clearly allocentric sympathy factors. Finally Close Others was also an allocentric sympathy type factor that can be considered as specific to the situation.

As expected, allocentric sympathy type concerns (Gift of Life, and Close Others) were the dominant motives at donating organs. The conformist type concerns (Duty), the pro-autic mastery type concerns (Living on Through a Receiver) and the autocentric sympathy type concerns (Positive Consideration), although clearly identified, received, however, much lower scores. As expected, the autocentric mastery type concerns and the conformist concerns were the dominant motives at not donating organs but their corresponding scores were comparatively low. These results are consistent with Apter and Spirn's (1997) findings.

These two studies also examined the associations between demographic and personality characteristics and the motives. The pattern of associations was consistent with our interpretation of the factors. As instance, Individualism was shown to be linked with gender (females scoring lower), negatively linked with education, and negatively linked with agreeableness. As another example, Positive Consideration was shown to be negatively linked with age, and positively linked with extraversion.

Finally, the two studies examined the association between the motives and the other variables, and the willingness to sign a donor card. As expected, willingness to sign was strongly associated with gender, even when the other predictors were taken into account. This result is consistent with Mocan and Tekin's (2007) findings. As expected, willingness to sign was strongly associated with both conformist motives, and with allocentric sympathy motives. Sque, Payne and Macleod Clark (2006) had already suggested that "gift of life" and "sacrifice" were the two key concepts for understanding of organ donor's decision-making. 
The dominant predictor was Preserving the Absolute Integrity of the Body; that is, a conformist type motive at not donating organs. Interestingly, the effect of Duty (the other conformist factor) and the effect of Gift of Life (the allocentric sympathy type factor) interacted with this factor. When Integrity scored high, the effect of the other factors was practically annihilated. This motive acted as a protected value. This result is consistent with early findings by Parisi and Katz (1986) who had already shown an interaction of a similar shape between positive and negative attitudes (see also Hübner \& Kaiser, 2006).

These findings help explain why, despite the fact that, as regards organ donation, positive views tend to dominate in our societies, and generous, altruistic motives are strongly endorsed, at the very moment of signing a donor card (or at the very moment of allowing the doctors to extract the organs from a relative's death body), many persons hesitate. Even if it is not very strongly expressed, the belief that the integrity of the body must be preserved acts as the main deterrent of donation. As stated by Sanner (2006, p. 148), "It is probably easier to explain legal rules, logistics, and surgery techniques than to help people come to terms with their partly subconscious and not always clearly articulated uneasiness". Changing people's religious or philosophical beliefs is difficult and it goes not without its own ethical issues. To what extent are we allowed to "change" some people's belief that the integrity of the body is a sacrosanct issue? In the case of many families, it would amount to change deep cultural habits and, in some cases, cultic habits. 


\section{References}

Apter, M. J. (Ed.) (2001). Motivational styles in everyday life: A guide to Reversal Theory. Washington, D.C.: American Psychological Association.

Apter, M. J. (2007). Reversal Theory: The dynamics of motivation, emotion and personality. Oxford: Oneworld Publications.

Apter, M. J., \& Spirn, N. (1997). Motives for donating blood. In Sveback, S. \& Apter, M. J. (Eds.), Stress and health: A reversal theory perspective (pp. 145-156). Washington, DC: Taylor and Francis.

Besser, A., Amir, M., \& Barkan, S. (2004). Who sign and organ transplant donor card? A study of personality and individual differences in a sample of Israeli students. Personality and Individual Differences, 36, 1709-1723.

Brug, J., Van Vugt, M., Van den Borne, B., Brouwers, A., \& Van Hooff, H. (2000). Predictors of willingness to register as an organ donor among Dutch adolescents. Psychology \& Health, 15, 357-368.

Callender, C. O., \& Miles, P. V. (2001). Obstacles to organ donation in ethnic minorities. Pediatric Transplantation, 5, 383-385.

Crowley-Matoka, M., \& Lock, M. (2006). Organ transplantation in a globalised world. Mortality, 11, 166-181.

Goldberg, L. R. (1999). A broad-bandwidth, public-domain, personality inventory measuring the lower-level facets of several Five-Factor models. In I. Mervielde, I. Deary, F., De Fruyt, and F. Ostendorf (Eds.), Personality Psychology in Europe (Vol. 7, pp. 7-28). Tilburg, The Netherlands: Tilburg University Press.

Hübner, G., \& Kaiser, F. G. (2006). The moderating role of the attitude-subjective norms conflict on the link between moral norms and intention. European psychologist, 11, 99-109. 
Matesanz, R., \& Dominguez-Gil, B. (2007). Strategies to optimize deceased organ donation. Transplantation Reviews, 21, 177-188.

Mocan, N., \& Tekin, E. (2007). The determinants of the willingness to donate an organ among young adults: Evidence from the United States and the European Union. Social Science and Medicine, in press.

Moloney, G., Hall, R., \& Walker, I. (2005). Social representations and themata: The construction and functioning of social knowledge about donation and transplantation. British Journal of Social Psychology, 44, 415-441.

Parisi, N., \& Katz, I. (1986). Attitudes towards posthumous organ donation and commitment to donate. Health Psychology, 5, 565-580.

Radecki Breitkopf, C. (2006). Perceived consequences of communicating organ donation wishes: An analyis of beliefs about defending one's decision. Psychology \& Health, 21, 481-497.

Radecki, C., \& Jaccard, J. (1997). Psychological aspects of organ donation: A critical review and synthesis of individual and next-of-kin donation decisions. Health Psychology, 16, 183-195.

Sanner, M. A. (2006). People's attitudes and reactions to organ donation. Mortality, 11, 133150).

Shanteau, J., \& Skowronski, J. J. (1990). The decision to donate organs: An information integration analysis. In Shanteau, J. \& Harris, R. J. (Eds.), Organ donation and transplantation: Psychological and behavioral factors (pp. 59-67). Washington: APA.

Skowronski, J. J. (1997). On the psychology of organ donation: Attitudinal and situational factors related to the willingness to be an organ donor. Basic and Applied Social Psychology, 19, 427-456. 
Sque, M., Payne, S., \& Macleod Clark, J. (2006). Gift of life or sacrifice?: Key discourses for understanding of organ donors' decision-making by families. Mortality, 11, 117-132)

Van den Berg, H., Mastead, A. R., Van der Pligt, J., \& Wigboldus, D. H. J. (2005). The role of affect in attitudes toward organ donation and donor-relevant decisions. Psychology and Health, 20, 789-802. 
Table 1.

Results of the Confirmatory Analysis Conducted on the Items about Willingness to Donate Organs.

\section{Factors}

One of the reasons that would encourage me to

$\begin{array}{llllll}\text { I } & \text { II } & \text { III } & \text { IV } & \text { V } & \text { VI }\end{array}$
donate organs would be that...

... my family would be compensated ${ }^{\mathrm{a}}$.

.86

... I have no direct descendants ${ }^{\mathrm{a}}$.

... my funerals would be paid ${ }^{\mathrm{b}}$.

... nobody has ever helped me in the past $\mathrm{t}^{\mathrm{b}}$.

... my religion or my philosophical views

encourages me to do $\mathrm{so}^{\mathrm{c}}$.

... everybody in my family would donate organs ${ }^{c}$.

$\ldots$ it is a more and more common decision among

people $^{\mathrm{d}}$.

$\ldots$ it is a civic act ${ }^{\mathrm{d}}$.

... it would attract the positive consideration of

close others ${ }^{\mathrm{e}}$.

$\ldots$ it is a very special experience ${ }^{\mathrm{e}}$.

... people would keep the impression that I was a

generous person ${ }^{\mathrm{f}}$.

... this decision is still considered as a somewhat

heroic one ${ }^{\mathrm{f}}$.

... there are many persons waiting for an organ ${ }^{\mathrm{g}}$. 
$\ldots$ it could save children ${ }^{\mathrm{g}}$.

... it can improve the quality of life of patients ${ }^{\mathrm{h}}$.

$\ldots$ it can save many lifes ${ }^{\mathrm{h}}$.

... I would have the impression of a form of psychic

continuity after death ${ }^{\mathrm{i}}$.

... the heart is where the emotions lie ${ }^{\mathrm{i}}$.

... I would be happy to live on through somebody

else ${ }^{\mathrm{j}}$

... I would have the impression that one part of

myself will be able to enjoy existence ${ }^{j}$.

... my organs would benefit a member of the family.

... someone would ask me personally. 


\section{Table 2.}

Results of the Confirmatory Analysis Conducted on the Items about Willingness Not to Donate Organs.

\section{Factors}

One of the reasons that would prevent me to donate

\begin{tabular}{llllll}
\hline I & II & III & IV & V & $t$
\end{tabular}
organs would be that...

... we must try to preserve the integrity of the human

body $^{\mathrm{a}}$.

... I consider that my body belongs to myself, and only

myself ${ }^{\mathrm{a}}$.

... I think that we must, above all, live the present ${ }^{\mathrm{b}}$.

... I am responsible for the complete integrity of my

body $y^{b}$.

... I do not really like life ${ }^{\mathrm{c}}$.

... there is not really a shortage of organs ${ }^{c}$.

... everybody in my family is willing to donate organs! $!^{\mathrm{d}}$

... I am not concerned by other's problems ${ }^{\mathrm{d}}$.

... it can considerably alter my physical appearance ${ }^{\mathrm{e}}$.

... the consequences for my own body are unknown ${ }^{\mathrm{e}}$.

... I will not be informed about what is going to be done

with them ${ }^{\mathrm{f}}$.

... I am not informed about the surgical procedure for

taking the organs ${ }^{\mathrm{f}}$. 
... the receiver will not known in advance that I am the

$.99 \quad 20.40$

donor ${ }^{\mathrm{g}}$

... I have no mean for knowing who is the receiver ${ }^{\mathrm{g}}$.

... the whole procedure is completely anonymous ${ }^{\mathrm{h}}$.

... I will not be able to meet before with the receiver ${ }^{\mathrm{h}}$.

... my family is hostile to the principle of organ donation ${ }^{\mathrm{i}}$.

... I would not like to hurt several members of my

family

... my close relationships are against organ donation ${ }^{\mathrm{j}}$.

... this would be going against my family's wishes ${ }^{\mathrm{j}}$.

$M$ 
Demographic Characteristics

\begin{tabular}{|c|c|c|c|c|c|}
\hline & Gender & Age & Education & Blood & Knows \\
\hline Financial Incentives & -.14 & $-.27^{*}$ & -.08 & $-.29^{*}$ & -.02 \\
\hline Humanistic or Religious Duty & .03 & -.03 & .15 & .02 & .06 \\
\hline Positive Consideration from Others & -.04 & $-.33^{*}$ & -.05 & -.14 & -.15 \\
\hline Gift of Life & $.19^{*}$ & .08 & $.25^{*}$ & $.19^{*}$ & -.15 \\
\hline Living on Through a Receiver & -.02 & -.12 & -.04 & .01 & .01 \\
\hline Close Other & .12 & -.05 & .04 & .06 & -.11 \\
\hline Integrity of the Body & -.17 & -.13 & -.14 & $-.21^{*}$ & $-.21^{*}$ \\
\hline Strict Individualism & $-.38^{*}$ & -.09 & $-.28^{*}$ & -.18 & -.00 \\
\hline Lack of Control over the Use of the Organs & -.01 & $-.24^{*}$ & -.04 & $-.20^{*}$ & -.02 \\
\hline Anonymity of the Procedure & -.10 & $-.22^{*}$ & -.04 & $-.21^{*}$ & .06 \\
\hline \multirow[t]{3}{*}{ Respecting Family Wishes } & -.09 & -.07 & -.12 & $-.20^{*}$ & -.02 \\
\hline & \multicolumn{4}{|c|}{ Personality } & Donor's \\
\hline & $\mathrm{N}$ & $\mathrm{E}$ & $\mathrm{C}$ & A & Card \\
\hline Financial Incentives & .09 & .15 & $.21^{*}$ & -.10 & -.18 \\
\hline Humanistic or Religious Duty & .05 & -.01 & .01 & $.25^{*}$ & $.28^{*}$ \\
\hline Positive Consideration from Others & .10 & $.26^{*}$ & .05 & -.00 & -.14 \\
\hline Gift of Life & .15 & -.04 & -.11 & $.35^{*}$ & $.32^{*}$ \\
\hline Living on Through a Receiver & $.27^{*}$ & .08 & .01 & .18 & .11 \\
\hline Close Other & .18 & -.06 & -.08 & $.25^{*}$ & .04 \\
\hline Integrity of the Body & $.19^{*}$ & .09 & -.02 & $-.19^{*}$ & $-.52^{*}$ \\
\hline Strict Individualism & -.07 & .11 & .02 & $-.40^{*}$ & $-.28^{*}$ \\
\hline
\end{tabular}


Lack of Control over the Use of the Organs

Anonymity of the Procedure

Respecting Family Wishes

$\begin{array}{lllll}.11 & -.04 & -.16 & .04 & -.31^{*} \\ .07 & .04 & -.02 & .06 & -.11 \\ .02 & .05 & .11 & -.05 & -.30^{*}\end{array}$

